\title{
BMJ Open Initial healthcare and coping preferences are associated with outcome 1 year after whiplash trauma: a multicentre 1-year follow-up study
}

\author{
Solbjørg Makalani Myrtveit, ${ }^{1,2}$ Tina Carstensen, ${ }^{3}$ Helge Kasch, ${ }^{4}$ Eva Ørnbøl, ${ }^{3}$ \\ Lisbeth Frostholm ${ }^{3}$
}

To cite: Myrtveit SM, Carstensen $\mathrm{T}$, Kasch $\mathrm{H}$, et al. Initial healthcare and coping preferences are associated with outcome 1 year after whiplash trauma: a multicentre 1-year followup study. BMJ Open 2015;5: e007239. doi:10.1136/ bmjopen-2014-007239

- Prepublication history and additional material is available. To view please visit the journal (http://dx.doi.org/ 10.1136/bmjopen-2014007239).

Received 19 November 2014 Revised 17 February 2015 Accepted 26 February 2015

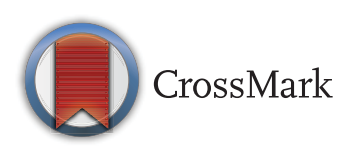

${ }^{1}$ Department of Clinical Science, University of Bergen, Bergen, Norway ${ }^{2}$ Division of Mental Health, Norwegian Institute of Public Health, Bergen, Norway ${ }^{3}$ The Research Clinic for Functional Disorders, Aarhus University Hospital, Aarhus, Denmark

${ }^{4}$ Department of Neurology, Danish Pain Research Centre, Aarhus University Hospital, Aarhus, Denmark

Correspondence to Solbjørg Makalani Myrtveit; makalani.myrtveit@med. uib.no

\section{ABSTRACT}

Objective: Individuals exposed to whiplash collisions have to cope with the stressful event as well as early physical symptoms. As in other chronic pain conditions, coping has been associated with outcome after whiplash. In this study, our aim was to examine whether initial coping preferences were associated with the development of chronic whiplash.

Design: Prospective study.

Setting: Primary care.

Methods: 740 acute whiplash patients were recruited from emergency units and general practitioners after car collisions in Denmark. Within 10 days postinjury, participants were asked what they believed could help them get better. At 12-month follow-up, the level of neck pain and capability to work was obtained. Whether coping preferences (baseline) were associated with outcome was investigated using multiple regression analyses.

Results: Persistent neck pain was most strongly associated with preferring medications (mean difference $=1.24(95 \% \mathrm{Cl} 0.67$ to 1.82$)$ ) and sickness absence (mean difference $=1.18(95 \% \mathrm{Cl} 0.53$ to $1.82)$ ). Reduced work capability was most strongly associated with preferring medications (OR $=3.53$ (95\% $\mathrm{Cl} 2.13$ to 5.86$)$ ), sickness absence (OR=3.05 $(95 \% \mathrm{Cl} 1.80$ to 5.17$))$ and being referred to a physiotherapist/chiropractor (OR=3.03 $(95 \% \mathrm{Cl} 1.33$ to 6.91)). Active coping was associated with better outcomes: Participants preferring to change their lifestyle were protected against reduced work capability (OR=0.11 (95\% Cl 0.01 to 0.78$)$ ). Individuals who wanted to keep living as usual only (no other preference reported) were protected against neck pain (mean difference $-1.62(95 \% \mathrm{Cl}-2.39$ to $-0.84)$ ) and reduced work capability ( $\mathrm{OR}=0.09(95 \%$ Cl 0.01 to 0.64$)$ ).

Conclusions: A simple nine-item measure of coping preferences is associated with the development of chronic neck pain and reduced capability to work following whiplash trauma and may be used to identify individuals at risk of poor recovery.
Strengths and limitations of this study

- The checklist investigating coping is not validated.

- All variables, including outcome and potential predictors, are self-reported.

- Follow-up design.

- Large sample size.

- Two clinically important outcomes potentially predicted by different factors were investigated.

- The checklist investigating coping is short, easy to understand and can investigate intentions to cope/coping preferences before coping takes place, and before pain has become chronic.

\section{OBJECTIVE}

After whiplash collisions, victims have to cope with the stressful and potentially lifethreatening event, as well as early physical symptoms resulting from the collision. A considerable proportion of individuals experiencing whiplash collisions develop chronic symptoms, ${ }^{1-3}$ reduced ability to work and impaired quality of life. ${ }^{45}$ Chronic whiplash is a complex and multifactorial disorder and the reasons for long-term suffering are still debated. ${ }^{6}$ As in other pain conditions, ${ }^{7}$ coping seems to be of prognostic importance in whiplash. ${ }^{8-11}$

Coping can be defined as purposeful efforts to manage stress, and in the field of chronic pain, coping efforts can be categorised into active and passive dimensions. ${ }^{7}$ Active coping refers to strategies where the individual makes an effort to function despite the pain or to distract themselves from the pain. In passive coping, individuals rely on others for help in pain control. ${ }^{7}$ Furthermore, the literature of coping can be classified according to orientation, either trait-dependent or state-dependent, and with 
a microanalytical or macroanalytical approach. ${ }^{12} 13$ This study looks at coping with a state orientation, on a microanalytical level, that is, coping is measured by way of specific strategies and coping styles, efforts and capacity, which can change over time.

Coping styles in the weeks following whiplash have been investigated in previous research. Passive coping has been found to predict delayed recovery, chronic symptoms and disability, ${ }^{8-11}$ while active coping generally seems to be unassociated with outcome. ${ }^{8-10}$ Also, research based on the data used in this study has shown that coping measured at 3 months postinjury is associated with neck pain at follow-up. ${ }^{14}$ As most studies investigating coping in whiplash have collected information on around 4-6 weeks postinjury or later, ${ }^{8-11} 14$ actual coping strategies might already have been modified, certain strategies being encouraged by health services, or affected by ongoing pain and other symptoms and/or the experience of success or failure of attempts to cope. Indeed, coping in whiplash has been shown to change over time, ${ }^{15}$ and a study investigating coping within 1 week after the whiplash collision found no association between coping and outcome. ${ }^{16}$

The aim of the present study was to describe which coping strategies patients believed would be helpful in the first days following an acute whiplash trauma. We further aimed to determine whether these straightforward coping preferences were associated with neck pain and reduced capability to work 1 year later. On the basis of previous research, we hypothesised that individuals preferring passive coping preferences and help-seeking behaviours would be at increased risk of neck pain and reduced capability to work.

\section{METHODS}

\section{Study design and population}

Patients with acute neck pain after whiplash collisions consulting emergency units or general practitioners were invited to participate in this two-centre study conducted by the Danish Pain Research Centre, Aarhus University Hospital, Aarhus, Denmark and the Back Research Centre, Odense University Hospital, Ringe, Denmark. Patients were included in the study from April 2001 to June 2003. The uptake area included the former four counties of Viborg, Aarhus, Vejle and Funen and in 2001 covered 1.7 million inhabitants.

Potential participants were informed of the study in a written invitation. The study included patients aged from 18 to 70 years who were experiencing neck pain within $72 \mathrm{~h}$ after being exposed to a rear-end or side-impact car collision. The study excluded patients who could not be examined within 10 days postcollision, had fractures, dislocations, amnesia or unconsciousness in relation to the collision, injuries other than whiplash injury, no symptoms, significant precollision physical or psychiatric disorders, significant self-reported preinjury neck pain during the preceding 6 months or alcohol or drug misuse.
Embedded in the entire study population, two randomised controlled trials (RCTs) were performed. ${ }^{17}{ }^{18}$ As no significant treatment effect was observed in any of the trials, no further reference will be made to the RCTs.

\section{Procedure}

Potential participants were interviewed by a project nurse in their homes within a median of 5 days postcollision $\left(\mathrm{q}_{1}=3, \mathrm{q}_{3}=6\right.$, $\left.\max 10\right)$. The nurse provided information about the project, performed the inclusion and asked patients to fill out a range of questionnaires. ${ }^{19}$ Twelve months later, participants completed a questionnaire on neck pain and work capability. Non-responders were contacted by phone regarding their work capability.

\section{Measures}

\section{Sociodemographics and collision severity}

Sociodemographic variables recorded included age, gender and education (dichotomous variable; those having completed compulsory education only and those having completed higher education).

The collision was described by self-reported information on $\delta$ speed (speed difference of cars involved) and extent of damage to the car. As in previous research, ${ }^{14} 19$ the speed categories for both cars were $0,0-30,30-80$, $80-110$ and $110 \mathrm{~km} / \mathrm{h}$ or more. The extent of damage to the car was defined as $0-30 \%, 30-50 \%, 50-80 \%$ or $80-100 \%$. If the $\delta$ difference was more than $30 \mathrm{~km} / \mathrm{h}$, this was defined as a risk factor, as was $50 \%$ or more damage to the car. From $\delta$ speed and $\%$ damage to car, a dichotomous variable was created: 'Not severe collision' and 'Severe collision'. Individuals were grouped in 'Not severe collision' if they were neither at risk in terms of $\delta$ speed or extent of car damage.

\section{Neck pain at baseline}

At baseline, neck pain was investigated using the statement: "This is your assessment of your average neck pain since the accident". Participants were asked to indicate their level of neck pain on a visual analogue 11-point box scale where 0 represented no neck pain and 10 the worst imaginable pain.

\section{Healthcare and coping preferences}

At baseline, patients were asked to report coping preferences, and were presented with a list of 13 items. The applied list is not part of any validated checklist for coping, but contains items similar to those used in other inventories, for instance, the Vanderbilt Pain Management Inventory (VPMI). ${ }^{7}$ Participants were asked which options they believed could help them get better. The answer possibilities for each coping preference were: 'right', 'mostly right', 'mostly wrong', 'wrong' and 'cannot answer'. A dichotomous variable was created for each option, grouping 'right' and 'mostly right' as 'agreeing' and 'mostly wrong' and 'wrong' as 'not agreeing'. As participants could indicate multiple preferences, groups are not exclusive. In the analyses, 
the coping preferences were grouped as active ('changing lifestyle' and 'keep living as usual') and passive ('take it easy, 'sickness absence', 'taking medications', 'being referred to a specialist', 'further medical investigations', 'being referred to a physiotherapist/ chiropractor' and 'talking to a doctor about symptoms') (see online supplementary appendix A).

The items 'surgery', 'change of diet', 'being referred to a psychologist' and 'having the doctor explain what is wrong' were not used in the final analyses. The item 'having the doctor explain what is wrong' was excluded as it was largely overlapping with the item 'talking to a doctor about symptoms'. The three others were excluded due to too low $\mathrm{n}$ for meaningful analyses $(\mathrm{n}=10, \mathrm{n}=43, \mathrm{n}=28$, respectively).

Finally, as there was a ceiling effect on the question 'keep living as usual' with $91 \%$ of patients agreeing, a new variable was computed including patients who agreed to this preference only, and excluding individuals who agreed to any other healthcare or coping preferences.

\section{Outcome measures at 12 months follow-up}

Neck pain: Neck pain during the preceding week (average) was rated on a visual analogue 11-point box scale, identical to the baseline measure of neck pain.

Capability to work: During the last month of the follow-up year, patients were asked to register days with sick leave and reduced working hours due to the collision in a calendar. ${ }^{17}$ As in previous research, ${ }^{19}$ a dichotomous variable was created, dividing individuals with unaffected work capability from individuals reporting reduced work capability due to whiplash. Non-responders were contacted by phone and asked about this specific item.

\section{Statistical analyses}

Age, gender and education were assessed. Participants' mean level of neck pain at follow-up was calculated, as was the percentage reporting reduced work capability.

Multiple regression models were used to investigate whether coping preferences at baseline were risk factors for poor outcome at follow-up. To avoid overfitting, the number of parameters in a linear regression model should not exceed $n / 15$; in this case at most $529 / 15 \approx 35$. In a logistic regression model, 10-15 cases for each explanatory parameter should be estimated; ${ }^{20}$ in this case between at most $98 / 10 \approx 10$ and $98 / 15 \approx 7$.

The selection of potential explanatory variables was made a priori and based on our hypotheses, which build on rational and theoretical choices and previous research. We chose to adjust for sociodemographic variables (age, gender, education), neck pain at baseline and collision severity, all in a linear fashion.

As neck pain was a continuous variable, multiple linear regression analyses were used for this variable. For the dichotomous variable work capability, multiple logistic regression analyses were used. Assumptions regarding the linear regression model were assessed by means of regression diagnostics. To investigate the model fit of the logistic regression model, the Hosmer-Lemeshow fit statistic was used; ${ }^{21}$ for discrimination the area under the receiver operating characteristic curve was evaluated. ${ }^{22} 23$

As multiple regression analyses were conducted, Bonferroni's method of taking multiple testing into account was used $;^{24}$ the required $p$ value of 0.05 was divided by the number of regression analyses (10). Our results thus had to present a $\mathrm{p}$ value below 0.005 to be significant at the 0.05 level.

Stata V.12 was used for all analyses. ${ }^{25}$

\section{RESULTS}

\section{Participation}

Among the 1495 patients assessed for eligibility, 740 patients joined the study (548 were ineligible (eg, 22.6\% could not be examined within 10 days after the collision, $17.7 \%$ had injuries other than the whiplash injury), 200 declined and 7 were excluded due to protocol violation). ${ }^{14}{ }^{19}$ In the final study population of $n=740$, the mean age was 34.91 years $(\mathrm{SD}=11.43), 64.1 \%$ were women and $49 \%$ had completed primary school only, while $51 \%$ reported higher formal education (high school or university/college). Among those reporting primary school only, $30.3 \%$ reported to be unskilled workers, while $40.8 \%$ were skilled workers.

Among the 200 participants declining participation, there were significantly more men than among participants. The 55 participants lost to follow-up have been described in previous research ${ }^{19}$; they did not differ from those completing the study with respect to gender, but were younger, more likely to be students or unemployed and more likely to report precollision unspecified pain. More information on inclusion, exclusion and differences between groups has been published previously. $^{14} 19$

The follow-up questionnaires (12 months postcollision) were completed by 672 participants. N=529 participants responded to the outcome parameter neck pain (overall response rate: $78.7 \%$ ). The response rate was higher for work capability $(\mathrm{n}=651$, overall response rate: $96.9 \%$ ), as non-responders were contacted by phone and asked about this specific item. ${ }^{19}$

\section{Coping preferences}

Almost all participants (91\%) reported that they wanted to keep living as usual. Following this, patients most commonly believed that being referred to a physiotherapist/chiropractor $(62.3 \%)$ and talking to a doctor about symptoms $(54.3 \%)$ would be helpful. Around half of the participants also believed that taking it easy $(44.5 \%)$ and further medical investigations (36.6\%) could help them. For further details on reported preferences, see table 1 .

Twelve months later, the mean level of reported neck pain was 2.92 (95\% CI 2.66 to 3.18 , range $0-10)$ and reduced work capability was reported by $15.1 \% \quad(\mathrm{n}=98$ 
Table 1 Healthcare and coping preferences $(n=740)$

Patients
agreeing, $\mathrm{n}(\%)$

Patients

disagreeing, $\mathbf{n}(\%)$

$673(91.0)$

$80(10.8)$

$63(8.5)$

Changing lifestyle

Passive coping preferences, including healthcare

Take it easy

Sick leave

Taking medications

Being referred to a specialist

Further medical investigations

Being referred to a physiotherapist/chiropractor

Talking to a doctor about symptoms
$329(44.5)$

$144(19.5)$

$181(24.5)$

$214(28.9)$

271 (36.6)

461 (62.3)

$402(54.3)$

$\begin{array}{ll}31(4.2) & 36(4.9) \\ \text { NA } & \text { NA } \\ 628(84.9) & 49(6.6)\end{array}$

$336(45.4)$

$520(70.3)$

$475(64.2)$

$347(46.9)$

$344(46.5)$

$152(20.5)$

$262(35.4)$
Patients indicating 'cannot answer', n (\%)

$36(4.9)$

(6.6)

$75(10.1)$

76 (10.3)

84 (11.4)

$179(24.2)$

125 (16.9)

$127(17.2)$

$76(10.3)$

*Individuals preferring to 'keep living as usual' and no other preferences.

NA, not applicable.

participants). Both outcomes were significantly related to a range of coping preferences (table 2, fully adjusted): The preferences most strongly associated with neck pain were taking medications (mean difference $=1.24$ (95\% CI 0.67 to 1.82$))$ and sickness absence (mean difference $=1.18$ (95\% CI 0.53 to 1.82$)$ ). This shows that the mean level of neck pain was 1.24 higher for those preferring medications compared with those not, and 1.18 higher for those preferring sickness absence compared with those not. Preferring to be referred to a physiotherapist/chiropractor was also associated with increased neck pain at follow-up.

Reduced working capability was most strongly associated with preferring to take medications $(\mathrm{OR}=3.53$ $(95 \%$ CI 2.13 to 5.86)), sickness absence (OR=3.05 (95\% CI 1.80 to 5.17$)$ ) and being referred to a physiotherapist/chiropractor (OR=3.03 (95\% CI 1.33 to 6.91$)$ ). Thus, for all these preferences, the odds of reduced capability to work were raised by more than three times compared with individuals not indicating the preferences. Preferring to be referred to a specialist also raised the risk of reduced capability to work at follow-up.

The response categories taking it easy, talking to a doctor about symptoms, further medical investigations and keep living as usual were not associated with either neck pain or reduced work capability at follow-up. However, keep living as usual only (and no other preferences) was protective, both with regard to neck pain (mean difference $=-1.62(95 \%$ CI -2.39 to -0.84$)$ ) and reduced work capability $(\mathrm{OR}=0.09 \quad(95 \%$ CI 0.01 to 0.64)). Participants who believed that a change of lifestyle could make them better were protected against reduced work capability at 12 months (OR=0.11 $(95 \%$ CI 0.01 to 0.78$)$ ).

After correcting for multiple testing (Bonferroni method); preferring sickness absence and medications remained significant risk factors for both neck pain and reduced work capability at follow-up. Preferring to keep living as usual only remained protective against neck pain.

Distribution of residuals was assessed by inspection of a series of scatter plots of residuals and each of the explanatory variables and of residuals and fitted values. Histograms and QQ-plots were inspected to assess normality of the residuals. None of the plots gave rise to concern.

\section{DISCUSSION}

\section{Summary of findings}

In this large, prospective study on acute whiplash trauma, patients' initial coping preferences were associated with neck pain and reduced work capability 1 year later. Preferring medications and sickness absence showed the strongest associations with chronic neck pain and reduced work capability. Preferring to be referred to a physiotherapist/chiropractor was particularly associated with reduced work capability, while patients who initially believed in changing their lifestyle were less likely to experience reduced capability to work (although not significantly after adjustment for multiple tests). Patients who wanted to keep living as usual and who did not endorse any other coping preferences were protected against neck pain and reduced capability to work (the latter association was not significant after adjustment for multiple tests).

\section{Strengths and limitations}

The main limitation of the study is related to the items used to assess coping preferences. As described above, the items are not part of any validated checklist for coping, but were chosen as we wanted to identify simple risk factors that could be easily noted by health personnel-without the use of extensive screening tools. Further, this study investigates preferences for coping, or intentions to cope, before coping efforts have actually 


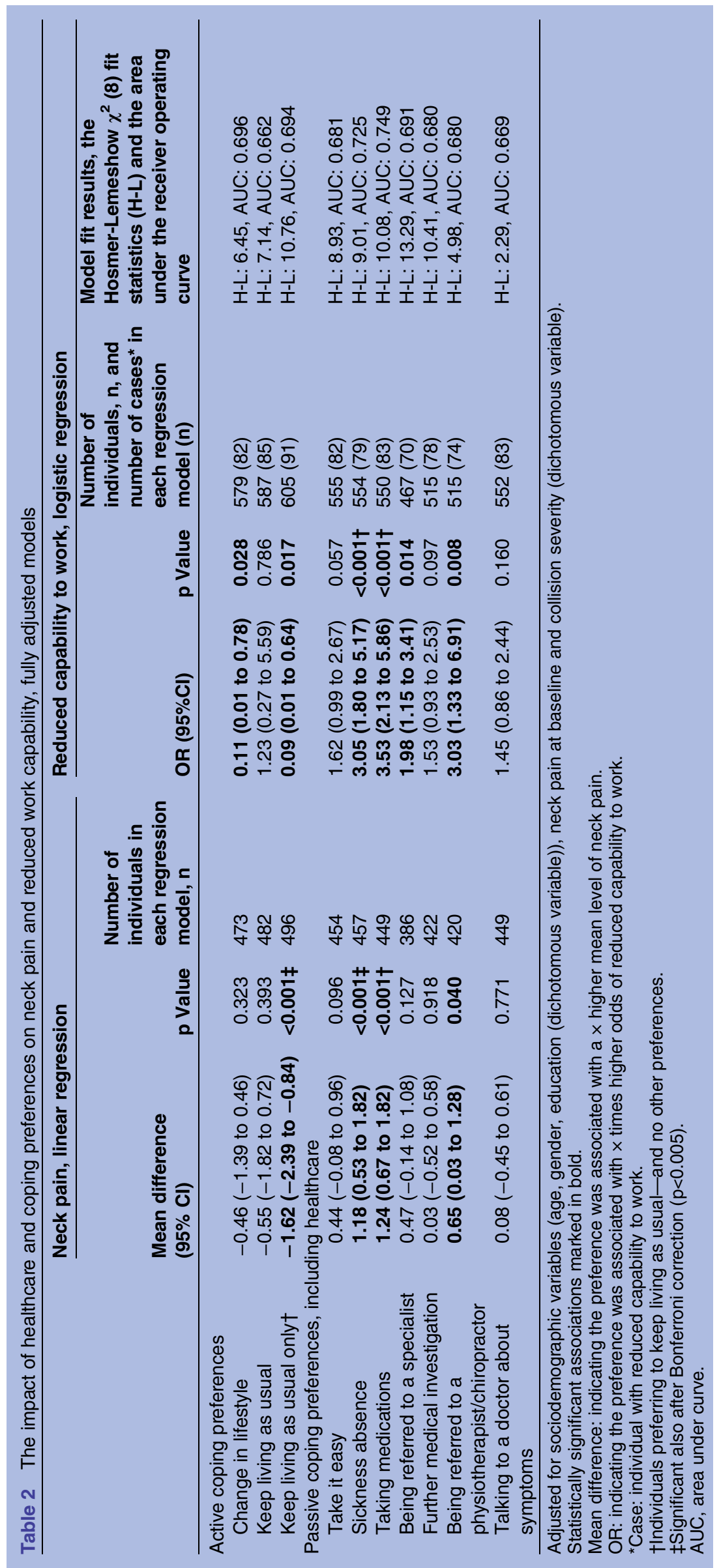


taken place and before pain has become chronic. Instruments that measure coping currently in use for chronic pain, like the VPMI, ${ }^{7}$ can therefore not be used.

Participants included in this study were referred by general practitioners and emergency units. As healthcare is free in Denmark, obvious selection bias due to socioeconomic differences was avoided. Including patients straight from the first-line health services (eg, emergency units and general practitioners) might be faster than, for instance, recruitment through insurance companies, minimising the risk of symptoms already being chronic at the time of inclusion. Furthermore, studies using data from insurance companies might possibly experience bias related to litigation issues.

A larger proportion of men than women declined participation. Findings regarding the prognostic importance of gender are inconsistent in the whiplash literature, ${ }^{26}$ but in this cohort, long-lasting neck pain is more common in women than men. ${ }^{14}$ Inclusion of more women could therefore lead to an overestimation of symptoms report. On the other hand, as shown by previous research on this cohort, ${ }^{19}$ more individuals lost to follow-up were unemployed or reported precollision pain. Preinjury pain especially seems to be associated with poor outcome, ${ }^{19} 27$ and this loss of participants to follow-up might have led to an underestimation of our results.

Some of the variables, for instance, work capability and collision severity, were dichotomised, leading to reduction of variation and loss of power. Another possible source of bias is that all variables, including outcome and potential predictors, are self-reported. In particular, the information regarding collision severity, such as the speed of the cars involved, may be difficult to self-report accurately. It has been suggested that some individuals might be inclined to exaggerate, overestimate or use high numerical values in rating tasks. In our study, if such high rating leads to increased risk of reporting passive coping as well as neck pain and disability at follow-up, this could lead to an overestimation of associations. At present, there is little knowledge regarding this issue. However, in an epidemiological study of musculoskeletal disorders, high or low rating behaviour was investigated, and no support for such theories was found. ${ }^{28}$

The major strengths of this study are the follow-up design, the large sample size and the high response rate. These factors allow the use of multiple logistic and linear regression models to investigate potential risk factors and to adjust for potential confounders. Furthermore, we were able to investigate two clinically important outcome measures, potentially predicted by different factors.

Being able to investigate work capability and not just neck pain was important also due to gender differences. In the general population, neck pain is more common among women than men. ${ }^{29}$ As pain before the injury predicts chronic whiplash symptoms, ${ }^{16} 3031$ and as chronic neck pain after whiplash in some studies seems to develop more often among women, ${ }^{14}{ }^{16}$ interpreting results related to neck pain only can be complicated.

Another advantage is that the information was collected soon after the trauma, reducing the chance of coping preferences being affected by postinjury experience or health services.

\section{Interpretation of findings}

The importance of coping measured 3 months after acute whiplash has been highlighted in a previous study applying the data used in this study ${ }^{14}$ : Increased risk of considerable neck pain 12 months after the collision was found for individuals with high scores on 'distraction' $(\mathrm{OR}=1.03,95 \%$ CI 1.01 to 1.05$)$, 'reinterpretation' $(\mathrm{OR}=1.03,95 \%$ CI 1.01 to 1.06), 'catastrophising' $(\mathrm{OR}=1.14,95 \%$ CI 1.10 to 1.18$)$, and 'praying and hoping' (OR=1.09, 95\% CI 1.05 to 1.13 ) at 3 months. In this study, we aimed to determine whether outcome could be predicted earlier, just days after the collision, and with far simpler measures. We found that straightforward coping preferences like preferring medications or further medical investigations were strongly associated with outcome. This implies that health personnel with this in mind can easily arrange for early identification of individuals at increased risk of poor recovery-without having to use extensive questionnaires.

Our finding of poor prognosis associated with passive coping as compared to active coping is in line with previous research. ${ }^{8-10}$ However, our findings add to these studies as information on coping preferences was collected within 10 days of the collision. Most previous studies have collected data on coping at later time points. ${ }^{8-11}$ In this study, coping preferences are not the result of living with chronic symptoms, or of already having experienced certain coping options as either beneficial or ineffective with regard to whiplash. Further, the risk of preferences already being affected by health services is smaller in this study than in studies with a later assessment of information. It should also be noted that coping intentions or coping preferences in this study were measured before coping efforts had actually taken place; most previous studies have investigated the coping methods currently used, ${ }^{8-11} 16$ while we investigate intentions to cope, or beliefs about what coping methods might be helpful.

A previous study investigating coping during the first week after whiplash found no association with outcome, and stated that recording coping strategies this early might not be useful for prognostic prediction. ${ }^{16}$ This study investigated to what extent specific coping strategies were used, employing the 42-item Coping Strategies Questionnaire (CSQ). There are several possible explanations for our findings contrasting these: First, the use of simple, straightforward items, rather than a long list and the investigation of subscales, might increase the likelihood of detecting associations. Also, this study investigated strategies used. As the mean time 
between the injury and the initial examination was only $3(\mathrm{SD}=2)$ days, ${ }^{16}$ participants might not yet have developed coping behaviour. When investigating intentions to cope, or beliefs about the benefits of coping, it might be possible to detect differences earlier.

It seems likely that injury severity and baseline neck pain would be associated with coping preferences and recovery. Neck pain at baseline has indeed been shown to predict outcome after whiplash, ${ }^{11} 32$ and head/neck pain is part of a risk assessment score for non-recovery in whiplash. $^{33}$ To account for this, we adjusted our analyses for neck pain at baseline as well as collision severity. The preferences for taking medications, sickness absence and being referred to a physiotherapist/chiropractor remained significant risk factors after adjustment, indicating that coping not only reflects a more severe injury. This is supported by previous findings. ${ }^{10}$

Patients' initial coping preferences might also be affected by preinjury, as well as personal and psychological factors. Preinjury health, for instance, somatic symptoms, ${ }^{31}$ poor self-rated health ${ }^{31} 34$ and pain, ${ }^{19}{ }^{27}$ all predict chronic symptoms after whiplash. Individuals with poor preinjury health might, due to experience, be more likely to indicate need for healthcare after whiplash collisions. Some of the associations found in this study could thus be explained by individuals with better precollision health being less likely to indicate need for health services and more likely to recover fast. Additionally, in whiplash as well as in other conditions, expectations to some extent predict outcome; ${ }^{35}$ individuals expecting to recover show better recovery. ${ }^{36} 37$ In line with this, negative illness perceptions ${ }^{35}$ and catastrophising ${ }^{38} 39$ predict chronic symptoms after whiplash collisions. Individuals expecting whiplash to have lasting consequences might be more likely to prefer passive coping and use of healthcare.

In our study, preferring to keep living as usual did not predict neck pain or capability to work. However, individuals reporting that they wanted to keep living as usual only, and reported no other coping preferences, were protected against neck pain and reduced capability to work (the latter association was not significant after adjustment for multiple tests). In other pain patients, active coping seems to be associated with better psychological adjustment ${ }^{7}$ and less depression and disability at follow-up. ${ }^{40}$ Most previous studies on whiplash have not found active coping to be protective. ${ }^{8-10}$ Still, exercise and mobilisation seem to give better outcomes than rest or neck collars ${ }^{41} 42$ and 'act as usual' (i.e., continuing to engage in normal, pre-injury activities) has been found to be preferable over sick leave and immobilisation. ${ }^{43}$

Coping styles might affect recovery through issues of compliance and choice of therapy; individuals high in passive coping and low in active coping the first week after the injury have been found to be more likely to take medications and less likely to attend active therapy. ${ }^{44}$ Our results suggest that it may be important to take passive coping preferences into account in future intervention studies as these may otherwise impede attempts to engage patients actively in treatment.

However, finding effective treatment for whiplash patients has proven difficult. A recent randomised controlled trial investigating individuals with acute whiplash found that multidisciplinary treatment (medications, physiotherapy and seeing a psychologist according to individual presentation) did not give benefit over usual care ${ }^{45}$ Also, in the cohort used in this study, immobilisation, 'act-as usual' (participants received information about whiplash injuries and the importance of staying active despite symptoms) and mobilisation had similar effects regarding prevention of pain, disability and capability to work at 12 months follow-up. ${ }^{17}$ In chronic whiplash, individually tailored physiotherapy exercise programmes have been found not to reduce pain more than simple advice alone. ${ }^{46}$ Thus, the efficacy of mobilisation is still debated.

In our study, indicating passive coping preferences or options related to healthcare increased the risk of poor recovery. This might indicate that healthcare, or the perceived need of it, might not only be ineffective but potentially harmful. Previous research has shown that high use of healthcare after whiplash collisions is associated with the development of symptoms and delayed recovery. ${ }^{31} 414748$ To patients with medically unexplained conditions, where chronic whiplash might be included, ${ }^{49} 50$ it seems that frequent testing and visits to doctors provide little reassurance and can heighten worry and anxiety. ${ }^{49}$ Indeed, symptoms can be amplified by becoming a patient, ${ }^{51}$ and once a person is diagnosed/labelled as ill, he or she can be regarded and treated in ways that make recovery more difficult. $^{49}$

\section{Implications}

Initial coping preferences are probably related to a multitude of factors, such as coping intentions, previous experiences with illness, generic health beliefs and specific perceptions of the nature of the current whiplash trauma. Regardless of what they are related to and composed of, this study suggests that straightforward information about patients' preferences for coping and healthcare gives information about the risk for poor outcome. Therefore, physicians and other health practitioners should take notice of participants' early expressions of coping preferences.

\section{CONCLUSION}

After whiplash collisions, participants' initial coping preferences were significantly associated with long-term neck pain and work capability, and also when adjusting for baseline neck pain and collision severity. We suggest that attention towards acute whiplash patients' coping preferences can lead to identification of individuals at high risk of poor recovery. 
Acknowledgements Data for this study were kindly provided from a study supported by Insurance \& Pension, The Research Foundation of Aarhus University. Data acquisition took place in collaboration between The Danish Pain Research Center, Aarhus University Hospital and The Back Research Center, Back Center Funen, Ringe, Denmark and The Research Clinic for Functional Disorders and Psychosomatics. The authors in particular thank Alice Kongsted and Tom Bendix for their help with collecting data for this study, and Henrik Kasch for his help with language.

Contributors SMM, EØ and LF designed the study and ran the analyses. SMM wrote the first draft. All authors contributed to the final write-up of the manuscript.

Funding This research received no specific grant from any funding agency in the public, commercial or not-for-profit sectors.

Competing interests None.

Ethics approval Local ethical committees

Provenance and peer review Not commissioned; externally peer reviewed.

Data sharing statement No additional data were available.

Open Access This is an Open Access article distributed in accordance with the Creative Commons Attribution Non Commercial (CC BY-NC 4.0) license which permits others to distribute, remix, adapt, build upon this work noncommercially, and license their derivative works on different terms, provided the original work is properly cited and the use is non-commercial. See: http:// creativecommons.org/licenses/by-nc/4.0/

\section{REFERENCES}

1. Wenzel HG, Mykletun A, Nilsen TI. Symptom profile of persons self-reporting whiplash: a Norwegian population-based study (HUNT 2). Eur Spine J 2009;18:1363-70.

2. Sterner Y, Gerdle B. Acute and chronic whiplash disorders-a review. J Rehabil Med 2004;36:193-209; quiz 210.

3. Myrtveit SM, Skogen JC, Wenzel HG, et al. Somatic symptoms beyond those generally associated with a whiplash injury are increased in self-reported chronic whiplash. A population-based cross sectional study: the Hordaland Health Study (HUSK). BMC Psychiatry 2012;12;129.

4. Lovell ME, Galasko CS. Whiplash disorders-a review. Injury 2002;33:97-101.

5. Mayou R, Tyndel S, Bryant B. Long-term outcome of motor vehicle accident injury. Psychosom Med 1997;59:578-84

6. Ferrari $\mathrm{R}$, Schrader $\mathrm{H}$. The late whiplash syndrome: a biopsychosocial approach. J Neurol Neurosurg Psychiatry 2001;70:722-6.

7. Brown GK, Nicassio PM. Development of a questionnaire for the assessment of active and passive coping strategies in chronic pain patients. Pain 1987;31:53-64.

8. Buitenhuis J, Spanjer J, Fidler V. Recovery from acute whiplash: the role of coping styles. Spine (Phila Pa 1976) 2003;28:896-901.

9. Carroll LJ, Cassidy JD, Cote P. The role of pain coping strategies in prognosis after whiplash injury: passive coping predicts slowed recovery. Pain 2006;124:18-26.

10. Carroll LJ, Ferrari R, Cassidy JD, et al. Coping and recovery in whiplash-associated disorders: early use of passive coping strategies is associated with slower recovery of neck pain and pain-related disability. Clin J Pain 2014;30:1-8.

11. Williamson E, Williams MA, Gates S, et al. Risk factors for chronic disability in a cohort of patients with acute whiplash associated disorders seeking physiotherapy treatment for persisting symptoms. Physiotherapy 2015;101:34-43.

12. Lazarus RS, Folkman S. Stress, appraisal and coping. New York: Springer Publishing Company, 1984.

13. Kaptein A, Weinman J. Health psychology. Oxford: The British Psychology Society and Blackwell Publishing, 2004.

14. Carstensen TBW, Frostholm L, Oernboel E, et al. Are there gender differences in coping with neck pain following acute whiplash trauma? A 12-month follow-up study. Eur J Pain 2012;16:49-60.

15. Söderlund A, Lindberg P. Whiplash-associated disorders-predicting disability from a process-oriented perspective of coping. Clin Rehabil 2003;17:101-7.

16. Kivioja J, Jensen I, Lindgren U. Early coping strategies do not influence the prognosis after whiplash injuries. Injury $2005 ; 36: 935-40$.
17. Kongsted A, Qerama E, Kasch H, et al. Neck collar, "act-as-usual" or active mobilization for whiplash injury? A randomized parallel-group trial. Spine (Phila Pa 1976) 2007;32:618-26.

18. Kongsted A, Qerama E, Kasch H, et al. Education of patients after whiplash injury: is oral advice any better than a pamphlet? Spine (Phila Pa 1976) 2008;33:E843-8.

19. Carstensen TB, Frostholm L, Oernboel E, et al. Post-trauma ratings of pre-collision pain and psychological distress predict poor outcome following acute whiplash trauma: a 12-month follow-up study. Pain 2008;139:248-59.

20. Peduzzi P, Concato J, Kemper E, et al. A simulation study of the number of events per variable in logistic regression analysis. J Clin Epidemiol 1996;49:1373-9.

21. Hosmer DW, Lemeshow S. Applied logistic regression. New York: Wiley and Sons, 2001.

22. Hanley JA, McNeil BJ. The meaning and use of the area under a receiver operating characteristic (ROC) curve. Radiology 1982;143:29-36.

23. Harrell FE. Regression modeling strategies: with applications to linear models, logistic regression, and survival analysis. Springer, 2001.

24. Bland JM, Altman DG. Multiple significance tests: the Bonferroni method. BMJ 1995;310:170.

25. StataCorp. Stata Statistical Software: Release 12. College Station, TX: Stata Corporation LP., 2011.

26. Sterling M. Physiotherapy management of whiplash-associated disorders (WAD). J Physiother 2014;60:5-12.

27. Atherton K, Wiles NJ, Lecky FE, et al. Predictors of persistent neck pain after whiplash injury. Emerg Med J 2006;23:195-201.

28. Toomingas A, Alfredsson L, Kilbom A. Possible bias from rating behavior when subjects rate both exposure and outcome. Scand J Work Environ Health 1997;23:370-7.

29. Côté P, Cassidy JD, Carroll LJ, et al. The annual incidence and course of neck pain in the general population: a population-based cohort study. Pain 2004;112:267-73.

30. Turner MA, Taylor PJ, Neal LA. Physical and psychiatric predictors of late whiplash syndrome. Injury 2003;34:434-7.

31. Myrtveit SM, Wilhelmsen I, Petrie KJ, et al. What characterizes individuals developing chronic whiplash?: The Nord-Trondelag Health Study (HUNT). J Psychosom Res 2013;74:393-400.

32. Côté $P$, Cassidy JD, Carroll L, et al. A systematic review of the prognosis of acute whiplash and a new conceptual framework to synthesize the literature. Spine (Phila Pa 1976) 2001;26: E445-58.

33. Kasch H, Qerama E, Kongsted A, et al. The risk assessment score in acute whiplash injury predicts outcome and reflects biopsychosocial factors. Spine (Phila Pa 1976) 2011;36(25 Suppl):S263-7.

34. Wenzel HG, Vasseljen $\mathrm{O}$, Mykletun $\mathrm{A}$, et al. Pre-injury health-related factors in relation to self-reported whiplash: longitudinal data from the HUNT study, Norway. Eur Spine J 2012;21:1528-35.

35. Gehrt TB, Wisbech Carstensen TB, Ørnbøl E, et al. The role of illness perceptions in predicting outcome after acute whiplash trauma: a multicenter 12-monthn follow-up study. Clin J Pain 2014;31:14-20.

36. Carroll LJ, Holm LW, Ferrari R, et al. Recovery in whiplash-associated disorders: do you get what you expect? J Rheumatol 2009;36:1063-70.

37. Holm LW, Carroll LJ, Cassidy JD, et al. Expectations for recovery important in the prognosis of whiplash injuries. PLoS Med 2008;5: e105.

38. Walton DM, Pretty J, MacDermid JC, et al. Risk factors for persisten problems following whiplash injury: results of a systematic review and meta-analysis. J Orthop Sports Phys Ther 2009;39:334-50.

39. Sullivan MJ, Adams $\mathrm{H}$, Martel MO, et al. Catastrophizing and perceived injustice: risk factors for the transition to chronicity after whiplash injury. Spine (Phila Pa 1976) 2011;36(25 Suppl):S244-9.

40. Jensen MP, Turner JA, Romano JM, et al. Coping with chronic pain: a critical review of the literature. Pain 1991:47:249-83.

41. Côté $P$, Soklaridis $S$. Does early management of whiplash-associated disorders assist or impede recovery? Spine 2011;36:S275-9.

42. Rosenfeld M, Gunnarsson R, Borenstein P. Early intervention in whiplash-associated disorders: a comparison of two treatment protocols. Spine (Phila Pa 1976) 2000;25:1782-7.

43. Borchgrevink GE, Kaasa A, McDonagh D, et al. Acute treatment of whiplash neck sprain injuries. A randomized trial of treatment during the first 14 days after a car accident. Spine (Phila Pa 1976) 1998:23:25-31.

44. Ferrari R, Louw D. Coping style as a predictor of compliance with referral to active rehabilitation in whiplash patients. Clin Rheumatol 2011;30:1221-5. 
45. Jull G, Kenardy J, Hendrikz J, et al. Management of acute whiplash: a randomized controlled trial of multidisciplinary stratified treatments. Pain 2013;154:1798-806.

46. Michaleff ZA, Maher CG, Lin CW, et al. Comprehensive physiotherapy exercise programme or advice for chronic whiplash (PROMISE): a pragmatic randomised controlled trial. Lancet $2014 ; 384$ : 133-41.

47. Ferrari R. Rewriting the book on whiplash. Lancet $2013 ; 381$ : 514-15.
48. Myrtveit SM, Skogen JC, Petrie KJ, et al. Factors related to non-recovery from whiplash. The Nord-Trøndelag Health Study (HUNT). Int J Behav Med 2013;21:430-8.

49. Barsky AJ, Borus JF. Functional somatic syndromes. Ann Intern Med 1999;130:910-21.

50. Berry H. Chronic whiplash syndrome as a functional disorder. Arch Neurol 2000;57:592.

51. Buitenhuis J, de Jong PJ. Fear avoidance and illness beliefs in posttraumatic neck pain. Spine (Phila Pa 1976) 2011;36(25 Suppl):S238-43. 


\section{Correction}

Myrtveit SM, Carstensen T, Kasch H, et al. Initial healthcare and coping preferences are associated with outcome 1 year after whiplash trauma: a multicentre 1-year followup study. BMJ Open 2015;5:e007239.

The number of regression analyses conducted is incorrectly stated on the second paragraph of page 3; 20 regression analyses were conducted, not 10. The paragraph should read "As multiple regression analyses were conducted, Bonferroni's method of taking multiple testing into account was used; the required $\mathrm{p}$ value of 0.05 was divided by the number of regression analyses (20). Our results thus had to present a $\mathrm{p}$ value below 0.0025 to be significant at the 0.05 level." This correction does not change any of the results or conclusions of the study, but the sentence below table 2: "†Significant also after Bonferroni correction $(\mathrm{p}<0.005)$ " should read "†Significant also after Bonferroni correction $(\mathrm{p}<0.0025)$ ".

Also, in table 2 the typographical signifier " $\nmid$ " should be replaced with " + " for the columns containing the $p$ values. Specifically, the $p$ value for the association between coping preference "sickness absence" and "reduced capability to work", the association between coping preference "take medications" and "neck pain", and the association between coping preference "take medications and "reduced capability to work" should be followed by "*" to indicate that they were significant also after bonferroni correction $(\mathrm{p}<0.0025)$.

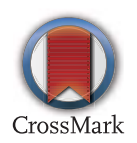

BMJ Open 2015;0:e007239corr1. doi:10.1136/bmjopen-2014-007239corr1 